\title{
ОЦЕНКА ПРОГНОСТИЧЕСКОГО ЗНАЧЕНИЯ ФЕРРИТИНА ПРИ КОВИД-ОБУСЛОВЛЕННЫХ ПОРАЖЕНИЯХ ЛЕГКИХ
}

\section{ESTIMATION OF THE PROGNOSTIC VALUE OF FERRITIN IN COVID-CONDITIONED LUNG LESIONS}

\section{Z. Kudryashova \\ N. Kobelevskaya}

Summary. Increases in serum ferritin levels in COVID-19 have been studied since the start of the pandemic, although the number of studies looking at the role of hyperferritinemia in COVID-19 continues to be significantly smaller than studies of other markers of inflammation.

An increase in ferritin levels is mainly considered as a diagnostic criterion for the cytokine curtain, as well as a tool for assessing the severity of the course of the disease and predicting death in COVID-19.

The aim of this study was to study the predictive value of serum ferritin levels and the dynamics of its indicators in patients with confirmed COVID-19 and acute interstitial pneumonia corresponding to CT 1 and CT 2 stages, and with the progression of lung lesions to CT 3 and CT 4 .

The study included 127 patients aged 42 to 83 years. An analysis of serum ferritin parameters and a comparison of the dynamics of ferritin levels between different groups of patients were carried out: without progression of viral lung damage and with its progression.

The results showed that ferritin levels can be used for prognostic purposes, because it can predict the risk of lung disease progression. However, the prognostic value of an isolated determination of ferritin is limited only by stage CT 1. At stages CT 2 - CT 3, a high level of ferritin is associated with the already completed progression of viral lung damage, although it correlates with its severity, but is not prognostic.

Keywords: COVID-19, ferritin, acute interstitial pneumonia.
Кудряшова Злата Владимировна Аспирант, Российский университет дружбы народов

Zlata-Kudryashova@mail.ru Кобелевская Наталья Викторовна К.м.н., дочент, Российский университет дружбы народов

Kobelevskaya.nat@mail.ru

Аннотация. Повышение уровня ферритина сыворотки крови при COVID-19 изучается с начала пандемии, хотя количество исследований, направленных на изучение роли гиперферритинемии при COVID-19, продолжает оставаться значительно меньше, чем исследований других маркеров воспаления.

Повышение уровня ферритина, главным образом, рассматривается, как диагностический критерий цитокинового штора, а также как инструмент оценки тяжести течения заболевания и прогноза летального исхода при COVID-19.

Целью настоящего исследования было изучение прогностической ценности уровня сывороточного ферритина и динамики его показателей у больных с подтвержденным COVID-19 и острой интерстициальной пневмонией, соответствующей КТ 1 и КТ 2 стадиям, и с прогрессированием поражения легких до стадий КТ 3 и КТ 4.

В исследование включено 127 пациентов в возрасте от 42 до 83 лет. Был проведен анализ показателей сывороточного ферритина и сравнение динамики уровня ферритина между различными группами пациентов: без прогрессирования вирусного поражения легких и с его прогрессированиeм.

Результаты показали, что уровень ферритина можно использовать с прогностической целью, т.к. он может предсказывать риск прогрессирования поражения легких. Однако прогностическая ценность изолированного определения ферритина ограничивается только стадией КТ 1. При стадиях КТ 2 - КТ 3 высокий уровень ферритина ассоциируется с уже свершившимся прогрессированием вирусного поражения легких, хотя и коррелирует с его тяжестью, но не является прогностическим.

Ключевые слова: COVID-19, ферритин, острая интерстициальная пневмония. 


\section{Ввемение}

Ф ерритин представляет собой комплекс гидроксифосфата железа с белком апоферритином, состоящий из двух типов субъединиц - H и L. Н тип касается первоначального выделения изоформ ферритина из сердца человека и определяется при электрофоретической миграции как более тяжелая субъединица. L относится к ферритину, выделенному из печени человека, который богат более легкой субъединицей. Гены, кодирующие H и L субъединицы ферритина человека, расположены на хромосомах 11q и 19q соответственно. [1]

Ферритин был открыт и выделен в кристаллической форме из селезенки лошади в 1937 году чешским физиологом Вилемом Лауфбергером. [2]

Спустя несколько десятилетий в 1972 году Аддисон и соавт., используя иммунорадиометрический анализ, количественно определили ферритин в сыворотке крови человека. [3]

В настоящее время определение уровня ферритина в сыворотке крови используется, главным образом, как индикатор запасов железа для диагностики и мониторинга заболеваний, связанных с перегрузкой или дефицитом железа. Ферритин отвечает за усвоение железа в организме, связывает свободные ионы железа и повышает его растворимость.

Уровень ферритина у мужчин изначально выше, чем у женщин. Его концентрация может выходить за рамки при нервном перенапряжении; злоупотреблении алкоголем. Повышение ферритина у женщин диагностируется при длительном приеме оральных контрацептивов. [4]

Ферритин регулирует энергетический баланс организма и термогенез. [5] Имеются данные о роли сывороточного ферритина в развитии метаболического синдрома [6], злокачественных новообразований [7], а также в формировании иммунитета, процессах ангиогенеза и воспалении [8].

Роль и место ферритина в воспалении продолжают обсуждаться. Существует мнение, что гиперферритинемия является «невинным сторонним» биомаркером неконтролируемого воспаления, который может быть использован для оценки эффективности лечения. Есть точка зрения, которая оценивает индукцию ферритина как защитную отрицательную регуляторную функцию. Другой взгляд рассматривает ферритин, как ключевой медиатор иммунной дисрегуляции, особенно при крайней гиперферритинемии, благодаря прямым иммуносупрессивным и провоспалительным эффектам. [9]
В отличие от бактериальных инфекций, вирусные инфекции обычно характеризуются повышенной уровни провоспалительного цитокина IL-18 в плазме вместе со значительно повышенными концентрациями ферритина в крови. [10]

В рамках рассмотрения роли ферритина в воспалении, обусловленном вирусом SARS-CoV-2, последнее представляет особый интерес.

Повышение уровня ферритина при COVID-19 изучается с начала пандемии.

Большинство таких исследований были ретроспективными по дизайну и проводились в отдельных центрах Китая. В целом, исследований, направленных на изучение роли гиперферритинемии продолжает оставаться значительно меньше, чем исследований таких маркеров воспаления, как прокальцитонин, С-реактивный белок, скорость оседания эритроцитов и сывороточный амилоид А.

До конца не выяснено, что является источником повышенной концентрации ферритина в плазме и потенциальной роли этого белка при COVID-19. Всё больше данных за роль макрофагов, продуцирующих цитокины, они составляют большинство иммунных клеток в паренхиме легких и могут быть ответственны за секрецию сывороточного ферритина. Кроме того, синтез ферритина может быть индуцирован несколькими воспалительными стимулами, включая цитокины, такие как IL-6 [11].

Повышение уровня ферритина, главным образом, рассматривается, как диагностический критерий цитокинового штора, а также как инструмент оценки тяжести и прогноза летального исхода при COVID-19. [12]

Согласно «Временным методическим рекомендациям: профилактика, диагностика и лечение новой коронавирусной инфекции (COVID-19)» версия 13 (14.10.2021) ферритин относится к прогностическим лабораторным маркерам. Указывается на увеличение ферритина, как острофазового белка, при неблагоприятном заболевания. Ферритин отнесен к параметрам с наибольшим значением для мониторинга состояния и оценки эффекта терапии при развитии ОРДС. Повышение уровня ферритина сыворотки крови также ассоциируется с гипервоспалением при COVID-19, механизм которого связан с активацией макрофагов/гепатоцитов. [13]

Таким образом, прогностическая роль уровня ферритина в риске прогрессирующего поражения легких у пациентов с COVID-19, как провоспалительного фак- 
Таблица 1

\begin{tabular}{|l|l|l|l|} 
Стадия ОИП по данным КТ & $\begin{array}{l}\text { Пациенты с прогрессированием } \\
\text { ОИП }\end{array}$ & $\begin{array}{l}\text { Пациенты без прогрессирования } \\
\text { ОиП }\end{array}$ & $\mathbf{p}$ \\
\hline КT 1 & $426,0(212,1-788,3)$ & $271,5(96,0-388,0)$ & 0,0001 \\
\hline KT 2 & $571,5(294,0-796,0)$ & $498,5(277,0-588,0)$ & 0,07 \\
\hline KT 3 & $1211,5(727,0-1445,0)$ & $977,0(507,0-1104,0)$ & 0,35 \\
\hline
\end{tabular}

тора развития цитокинового шторма, требует дальнейшего изучения.

\section{Захача исслеАования}

Изучить прогностическую ценность уровня сывороточного ферритина и динамики его показателей у больных с подтвержденным COVID-19 и острой интерстициальной пневмонией (ОИП), соответствующей КТ 1 и КТ 2 стадиям, и с прогрессированием поражения легких до стадий КТ 3 и КТ 4.

\section{Материалы и метоны}

Проведен ретроспективный анализ историй болезни 127 пациентов (65 мужчин и 62 женщин) в возрасте от 42 до 83 лет, находившихся на стационарном лечении с января по декабрь 2021 года, с подтвержденным COVID-19 (экспресс-тест на выявление антигенов SARSCoV-2, ПЦР для выявления PHK SARS-CoV-2, повышение (gM), госпитализированных с клинико-рентгенологической картиной острой интерстициальной пневмонии, соответствовавшей степени тяжести КТ 1 или КТ 2 стадиям, которые либо были выписаны в связи с отсутствием прогрессирования пневмонии, либо имели прогрессирование поражения легких до КТ 3 и КТ 4 стадий.

Уровень сывороточного ферритина определялся всем пациентам, госпитализированным с КТ 1 и КТ 2 на 1-е, 3-е, 5-е сутки от момента госпитализации, а также в случае прогрессирования вирусного поражения легких до стадии КТ 2 (при исходной стадии КТ 1) и КТ 3 или КТ 4 (при исходной стадии КТ 1-2) на 1-е, 3-е и 5-е сутки от момента выявления более высокой стадии.

Определение уровня сывороточного ферритина производилось на биохимическом анализаторе Immulite 2000 ХРі (методом ферментативно-усиленной хемилюминесценции).

Критериями невключения были: беременность, наличие анемии и любых воспалительных заболеваний другой локализации, злокачественные опухоли, и лю- бые другие заболевания, которые могут оказать влияние на уровень ферритина в крови.

Всем пациентам с высокими значениями ферритина для исключения нарушений обмена железа определяли уровни сывороточного железа и трансферрина.

Все пациенты получали терапию в зависимости от степени тяжести заболевания, согласно «Временным методическим рекомендациям: профилактика, диагностика и лечение новой коронавирусной инфекции (COVID-19)» версии 9 (с 26.10.2020), 10 (с 08.02.2021), 11 (07.05.2021), 12 (с 21.09.2021), 13 (c 14.10.2021).

Статистическая обработка результатов проводилась с помощью пакета программного обеспечения SPSS18.0.

Проверку нормальности распределения данных выполняли с помощью критериев Колмогорова - Смирнова. Согласно проведенной проверке, полученные данные не подчинялись закону нормального распределения. Поэтому в описательной статистике значения числовых показателей представлены медианой (Me) и межквартильным размахом (IQR) в виде значений $25 \%$ нижнего и 75\% верхнего квартилей через точку с запятой (25\%; 75\%). Аналитическая статистика выполнялась с использованием U-критерия Манна - Уитни. Анализ рисков проводился методом «латинского квадрата» с расчётом отношения шансов (ОШ). Степень и векторность влияния оценивалась по значениям экспоненты регрессионного коэффициента $\mathrm{B}(\mathrm{ExpB}=\mathrm{OШ})$, представляющего собой отношение шансов вероятности бинарного события с учётом 95\% доверительного интервала. Значение вероятности (р) менее 0,05 (двухсторонняя проверка значимости) демонстрировало статистическую достоверность.

\section{Результаты и их обсужьение}

Уровни ферритинемии у пациентов с COVID-19 с прогрессированием поражения легких в виде острой интерстициальной пневмонии (ОИП) и без прогрессирования представлены в табл. 1 
Из таблицы 1 видно, что не у всех пациентов исходно (при КТ 1) значения ферритина выходили за верхнюю границу нормы. Ни у одного пациента, исходно имевшего нормальные показатели ферритина ( $\mathrm{n}=15$ $(11,8 \%))$, не отмечено прогрессирования ОИП. Среди пациентов с КТ 1 исходно повышенные показатели имели 32 человека (25,2\%). Основное значение в плане прогноза прогрессирования ОИП имела динамика уровня ферритина на фоне лечения к 5-му дню наблюдения. У 13 пациентов (10,2\%) отмечалось снижение уровня сывороточного ферритина, и в целом он не превысил уровень 400 мкг /л. У 19 (14,9\%) пациентов, не смотря на лечение к 3-му дню терапии, отмечено повышение уровня ферритина 426,0 (212,1796,3), что ассоциировалось с выявлением на КТ ОГК прогрессирования ОИП до КТ-2 в среднем через 2-3 дня после лабораторных данных. Выполнение КТ в более ранние сроки, например на 3 день лабораторного контроля, не выявляло ухудшение рентгенологической картины. В целом уровень ферритина у этих пациентов не превысил значений 800 мкг /л. Различия в уровнях сывороточного ферритина у пациентов без прогрессирования и с прогрессированием ОИП у пациентов с исходной картиной КТ 1 были статистический достоверными.

С КТ 2 стадией интерстициального поражения легких мы наблюдали 51 пациента (40,1\%). Это 14 пациентов, у которых отмечалось прогрессирование ОИП в стационаре, и 37 пациентов, госпитализированных уже с данной стадией. У пациентов с этой стадией отмечался более высокий исходный уровень ферритина, чем при КТ 1. При оценке динамики ферритина отмечено, что к 5-му дню у пациентов без прогрессирования ОИП (18,1\%) наблюдалось снижение показателей и в целом они не превысили 600 мкг /л, а у 28 (22,0\%) пациентов с прогрессированием ОИП отмечался рост показателей, но в целом они не превысили 800 мкг /л. Однако данная разница оказалась статистически не достоверной.

Сходная динамика показателей ферритина был и у пациентов с КТ 3. Таких пациентов было 44 (28 с прогрессированием КТ 2 до КТ 3 и 16 пациентов госпитализированных с такой стадией). Пациенты при этой стадии исходно имели высокий уровень ферритина крови и динамика снижения его показателей на фоне терапии не была столь выраженной, как при КT 1 и КТ 2 стадии. Даже у пациентов, у которых не отмечалось прогрессирование ОИП до КТ 4, ферритинемия достигала значений <600 мкг /л только в среднем к 10 дню терапии. У пациентов без прогрессирования ОИП в целом уровень ферритина не превысил 1200 мкг /л. У пациентов с развитием КТ 4 стадии уровень ферритина в целом был не меньше 1500 мкг /л. Однако разница показателей была статистический не достоверной.

Интересную группу представляют пациенты, у которых при картине ОИП, соответствующей стадии КТ 1, отмечался исходный уровень ферритина >1500 мкг /л. У Таких пациентов наблюдалось очень быстрое прогрессирование ОИП до КТ 3-4 в течении 3-5 дней, а также высокий риск летального исхода.

В рамках данного исследования мы не изучали связь уровня ферритина с летальными исходами, но отметили, что у умерших пациентов, особенно при КТ 3-4, скорость нарастания уровня ферритина была больше, чем при благоприятном исходе.

Результаты нашего исследования показали зависимость уровня ферритина сыворотки крови от степени тяжести ОИП, что безусловно оправдывает использование данного показателя как маркера острой фазы воспаления при COVID-19. Уровень ферритина был выше референсных значений и возрастал при прогрессировании воспалительного процесса в легких, что подтверждает его диагностическое значение для оценки степени тяжести ОИП.

При прогрессировании ОИП уровень ферритина становился выше, не смотря на лечение, что, по-видимому, отражает увеличение активности воспалительных реакций в легочной ткани, на это указывают и другие исследования. [12]

Однако, что касается оценки уровня ферритина с целью прогноза прогрессирования ОИП, то наше исследование не смогло в полной мере его доказать.

Прогностически значимым уровнем ферритина является его повышение на фоне проведения рациональной терапии у пациентов с КТ 1, что статически достоверно прогнозирует высокий риск прогрессирования ОИП до КТ 2 (ОШ 4,3; ДИ 95\%; $p=0,005$ ).

Так же и его исходно высокие значения при КТ 1 (>1500 мкг /л) статически достоверно прогнозирует высокий риск прогрессирования ОИП до КТ 3-4 (ОШ 7,2; ди 95\%; $p=0,001)$.

В остальных случаях повышение уровня ферритина происходило параллельно с прогрессированием КТ картины ОИП и коррелировало с тяжестью её течения.

Безусловно, данное исследование ограничено небольшой выборкой пациентов, что обусловлено широкими критериями невключения. Но благодаря этому 
полученные результаты являются достаточно «чистыми» в плане независимости от сопутствующей патологии пациентов.

\section{Зак^ючение}

Изучение роли различных биологически активных веществ в оценке тяжести течения и вероятности неблагоприятного исхода поражения легких при COVID-19 в настоящее время является одним из активно разрабатываемых научно-практических направлений. Связано это с тем, что получение такой информации важно в плане осуществления индивидуального подхода к лечению и коррекции лечебной тактики у таких пациентов, а именно: определение показаний для госпитализации, решение вопроса о необходимости оказания помощи в отделении реанимации, более точной оценке эффективности лечебной тактики.
Одним из привлекающих к себе внимание биомаркеров является ферритин, концентрация которого в крови, особенно при тяжелом течении COVID-19, значительно повышается.

Результаты многих исследований показывают, что высокий уровень ферритина связан с плохим исходом заболевания.

Наше исследование показало, что данный показатель можно использовать с прогностической целью, т.к. он может предсказывать риск прогрессирования поражения легких. Однако прогностическая ценность изолированного определения ферритина ограничивается только стадией КТ 1. При стадиях КТ 2 - КТ 4 высокий уровень ферритина ассоциируется с уже свершившимся прогрессированием вирусного поражения легких, хотя и коррелирует с его тяжестью.

\section{ЛИТЕРАТУРА}

1. Worwood M, Brook JD, Cragg SJ, et al. Assignment of human ferritin genes to chromosomes 11 and 19q13.3-19qter. Hum Genet. 1985;69:371-374.

2. Laufberger V. Sur la cristallisation de la ferritine. Bulletin de la Societe de chimie biologique. 1937;19:1575-1582.

3. Addison GM, Beamish MR, Hales CN, et al. An immunoradiometric assay for ferritin in the serum of normal subjects and patients with iron deficiency and iron overload. Clin Pathol. 1972 Apr; 25(4):326-9.

4. Knovich MA, Storey JA, Coffman LG, et al. Ferritin for the clinician. Blood Rev. 2009 May;23(3):95-104. doi: 10.1016/j.blre.2008.08.001

5. Blankenhaus B, Braza F, Martins R, et al. Ferritin regulates organismal energy balance and thermogenesis. Mol Metab. 2019 Jun;24:64-79. doi: 10.1016/j. molmet.2019.03.008.

6. Victoria Abril-Ulloa, Gemma Flores-Mateo, Rosa Solà-Alberich, et al. Ferritin levels and risk of metabolic syndrome: meta-analysis of observational studies. Review BMC Public Health. 2014 May 21;14:483. doi: 10.1186/1471-2458-14-483.

7. Fan K, Gao L, Yan X. Human ferritin for tumor detection and therapy. Rev Nanomed Nanobiotechnol. 2013 Jul-Aug;5(4):287-98. doi: 10.1002/wnan.1221.

8. Wang W, Knovich MA, Coffman LG, et al. Serum ferritin: Past, present and future. Biochim Biophys Acta. 2010 Aug;1800(8):760-9. doi: 10.1016/j. bbagen.2010.03.011.

9. Kernan KF, Carcillo JA. Hyperferritinemia and inflammation. Int Immunol. 2017 Nov 1;29(9):401-409. doi: 10.1093/intimm/dxx031.

10. I Jeroen Slaats, Jaap Ten Oever, Frank L van de Veerdonk. L-13/IL-6/CRP and IL-18/ferritin: Distinct Inflammatory Programs in Infections PLoS Pathog. 2016 Dec 15;12(12): e1005973. doi: 10.1371/journal.ppat.1005973.

11. Jenifer Gómez-Pastora, Mitchell Weigand, James Kim, et al. Hyperferritinemia in critically ill COVID-19 patients — Is ferritin the product of inflammation or a pathogenic mediator? Clin Chim Acta. 2020 0ct;509:249-251. doi: 10.1016/j.cca.2020.06.033.

12. Linlin Cheng, Haolong Li, Liubing Li, et al. Ferritin in the coronavirus disease 2019 (COVID-19): A systematic review and meta-analysis J Clin Lab Anal. 2020 0ct;34(10): e23618. doi: 10.1002/jcla.23618.

13. https://static-0.minzdrav.gov.ru/system/attachments/attaches/000/058/211/original/BMP-13.pdf

( Кудряшова Злата Владимировна ( Zlata-Kudryashova@mail.ru ), Кобелевская Наталья Викторовна ( Kobelevskaya.nat@mail.ru ). Журнал «Современная наука: актуальные проблемы теории и практики» 